\title{
Association of TERT polymorphisms and risk of coronary heart disease in a Chinese Han population
}

\author{
Hongmei Han ${ }^{1}$, Jianxia Zhang ${ }^{1}$, Jianghong Hou ${ }^{1}$, Haibo Wang ${ }^{1}$, Jianpeng Zheng ${ }^{1}$, \\ Huan Wang ${ }^{1}$, Zhong Zhong ${ }^{1}$, Yijin Wang ${ }^{1}$, Xiaoni Wang ${ }^{1}$, Bei Yang ${ }^{1}$, Lei Wang ${ }^{1}$, \\ Dangjun Quan ${ }^{1}$ and Junnong Li ${ }^{1}$ \\ ${ }^{1}$ Department of Cardiovascular Medicine, Weinan Central Hospital, Weinan 714000, Shaanxi, China \\ Correspondence to: Junnong Li, email: drjunnongli@163.com \\ Keywords: coronary heart disease (CHD), TERT, telomere, single nucleotide polymorphisms (SNP), case-control study \\ Received: April 13, 2017 \\ Accepted: May 11, 2017 \\ Published: June 28, 2017 \\ Copyright: Han et al. This is an open-access article distributed under the terms of the Creative Commons Attribution License 3.0 \\ (CC BY 3.0), which permits unrestricted use, distribution, and reproduction in any medium, provided the original author and source \\ are credited.
}

\section{ABSTRACT}

Genome-wide association studies have identified that TERT gene was associated with telomere length and age-related diseases. However, little study directly focused on the association between TERT gene polymorphisms and risk of coronary heart disease (CHD). We conducted a case-control study to examine the effect of TERT polymorphisms on CHD risk among 596 CHD patients and 603 healthy controls from China. Five significant single nucleotide polymorphisms (SNP) in TERT were selected and genotyped using Sequenom Mass-ARRAY technology. Odds ratios (OR) and $\mathbf{9 5 \%}$ confidence intervals (CIs) were calculated using unconditional logistic regression adjusting for age and gender. Allelic model analysis revealed that for TERT rs10069690, allele frequency distributions differed between cases and controls (OR= $1.267,95 \% C I=1.018-1.576 ; p=0.034)$. Genotypic model analysis revealed that genotype frequency distributions of rs10069690 differed between cases and controls after adjusted by age and sex (TC vs. CC: adjusted $O R=1.352,95 \%$ CI $=1.007-$ $1.815 ; p=0.045)$. Genetic model analysis revealed that rs 10069690 was associated with an increased risk of CHD under co-dominant, dominant, over-dominant and logadditive models. After adjustments, it remained significant under over-dominant model (adjusted OR $=1.35,95 \% \mathrm{CI}=1.01-1.81 ; p=0.044$ ). Our results shed new light on the association between telomere-related gene TERT polymorphisms and CHD susceptibility in a Chinese Han population.

\section{INTRODUCTION}

Coronary heart disease (CHD), including myocardial infarction, angina pectoris and arteriosclerosis of the coronary arteries, is the leading cause of disability and mortality world-wide [1-3]. Previous studies have revealed that $\mathrm{CHD}$ is a complex polygenic disease, and genetic factors are crucial to an individual's susceptibility to CHD. [4]. To date, genome-wide association studies (GWAS) have identified more than 40 common variants associated with the risk of CHD [5, 6]. However, this is not enough to explain the etiology of CHD. In recent years, researchers were still working on looking for novel susceptibility locus for CHD and replicating significant single nucleotide polymorphisms (SNP) in different populations.

Telomeres are located at the ends of chromosomes, which consist of tandem (TTAGGG) ${ }_{\mathrm{n}}$ nucleotide repeats and some binding proteins [7]. The average telomere length is about $10-15 \mathrm{~kb}$ in human somatic cells, and shorten in most cells with aging [8]. Telomere plays a significant role in maintaining the stability and integrity of the genome [9]. Telomerase reverse transcriptase is required to keep the maintenance of telomere [10]. Loss of telomere function and infinite proliferation leads to genomic instability and chromosomal abnormalities, which may promote carcinogenesis [11]. 
Table 1: Characteristics of cases and controls included in this study

\begin{tabular}{lccc}
\hline Variables & Case $(\mathbf{N}=\mathbf{5 9 6})$ & Control $(\mathbf{N}=\mathbf{6 0 3})$ & $p$-value \\
\hline Sex, No. $(\%)$ & 376 & & $<0.001^{\mathrm{a}}$ \\
Male & 220 & 469 & \\
Female & $61.44 \pm 11.16$ & $48.24 \pm 13.05$ & $<0.001^{\mathrm{b}}$ \\
Mean age \pm SD & & & \\
\hline
\end{tabular}

a The $p$ value was calculated from Pearson's chi-square tests.

b The $p$ value was calculated by Welch's t tests.

$\mathrm{SD}$, standard deviation.

The TERT gene at $5 \mathrm{p} 15.33$ encodes the catalytic subunit of telomerase reverse transcriptase, which is an important component of telomerase. GWAS studies have identified that TERT gene was associated with telomere length and age-related diseases [12]. However, little study directly focused on the association between TERT gene polymorphisms and CHD risk. We performed a casecontrol study to analyze the association between five SNPs in TERT and the risk of CHD in a Chinese Han population.

\section{RESULTS}

A total of $596 \mathrm{CHD}$ cases (376 men and 220 women; mean age, $61.44 \pm 11.16$ years) and 603 controls (469 men and 134 women; mean age, $48.24 \pm 13.05$ years) were included in the study. The clinical characteristics of the cases and controls are shown in Table 1. There were significant differences in the age and gender distributions between the case and control groups $(p<0.05)$. Multivariate analyses were adjusted for age and sex.

The minor allele frequencies (MAFs) of the analyzed SNPs in the case and control groups are shown in Table 2. All SNPs were in Hardy-Weinberg equilibrium (HWE) in the controls $(p>0.05)$. The MAFs of the SNPs in the control group were similar to those reported for the HapMap Asian population. Using chi-square tests, we determined that rs10069690 was associated with a 1.267 fold increase in the risk of CHD $(95 \% \mathrm{CI}=1.018-1.576$; $p=0.034)$. No significant associations were detected between the other SNPs and CHD risk.

The genotype frequencies of the TERT polymorphisms are shown in Table 3. Compared to the CC genotype, the frequency of the TC genotype of rs 10069690 polymorphism in the case group significantly differed from the controls (TC vs. CC: $\mathrm{OR}=1.452,95 \%$ $\mathrm{CI}=1.122-1.879 ; p=0.004)$, suggesting that $\mathrm{rs} 10069690$ increased the risk of CHD. It is remained significant after adjusted by age and sex (TC vs. CC: adjusted OR $=1.352$, $95 \% \mathrm{CI}=1.007-1.815 ; p=0.045)$.

We assumed that the minor allele of each SNP was a risk factor compared to the wild-type allele. Five genetic models (co-dominant, dominant, recessive, overdominant and log-additive) were applied to analyze the associations between the SNPs and CHD risk using an unconditional logistic regression analysis with adjustments for age and gender (Table 4). We found that rs10069690 was associated with an increased risk of CHD under codominant, dominant, over-dominant and log-additive models. After adjustments, it remained significant under over-dominant model (adjusted OR $=1.35,95 \% \mathrm{CI}=$ $1.01-1.81 ; p=0.044)$.

We further characterized the SNPs in TERT SNPS using LD and haplotype analyses. One block including rs10069690 and rs2242652 was detected (Figure 1). However, we didn't found any significant result in the haplotype analysis (Table 5).

\section{DISCUSSION}

In this study, we investigated the associations between five selected TERT SNPs and risk of CHD in a Chinese Han population. We found that rs10069690 is associated with an increased risk of CHD. Our results suggest that the polymorphisms of TERT may play an important role in the risk of CHD in a Chinese Han population.

TERT gene encodes the telomerase reverse transcriptase, which is really important to keep the balance of telomere length [13]. It has been demonstrated that mean leucocyte telomere length is a predictor of the development of CHD, and differences in biological ageing might contribute to the risk and variability in age of onset of CHD [14]. In the present study, we further demonstrated that TERT gene polymorphisms were associated with CHD risk, which shed new light on the association between telomere length and CHD risk. Actually, TERT has been associated with many types of cancer, including lung cancer, urinary bladder, prostate and cervix cancer, and so on [15]. We suggested that TERT gene may have relationship with cancers and disease by influencing the balancing the telomere length; however, the mechanistic details have not yet been elucidated.

Previous association studies have found many SNPs associated with CHD risk in different populations. Samani et al. found that rs1333049, rs3008621, rs599839, rs501120, rs2943634 and rs6922269 were associated with 
Table 2: Allele frequencies in cases and controls and odds ratio estimates for CHD

\begin{tabular}{|c|c|c|c|c|c|c|c|c|c|}
\hline \multirow{2}{*}{ SNP ID } & \multirow{2}{*}{ Band } & \multirow{2}{*}{ Position } & \multirow{2}{*}{ Gene } & \multirow{2}{*}{ Alleles A $\mathbf{A}^{\mathrm{a}} \mathbf{B}$} & \multicolumn{2}{|c|}{ MAF } & \multirow{2}{*}{$\begin{array}{c}\text { HWE } \\
p \text {-value }\end{array}$} & \multirow{2}{*}{ ORs(95\%CI) } & \multirow{2}{*}{$\begin{array}{c}p \text { - } \\
\text { value }\end{array}$} \\
\hline & & & & & Case & Control & & & \\
\hline rs2075786 & $5 \mathrm{p} 15.33$ & 1266310 & TERT & $\mathrm{G} / \mathrm{A}$ & 0.163 & 0.162 & 0.879 & $1.003(0.806-1.248)$ & 0.981 \\
\hline rs 10069690 & $5 \mathrm{p} 15.33$ & 1279790 & TERT & $\mathrm{T} / \mathrm{C}$ & 0.180 & 0.147 & 0.190 & $1.267(1.018-1.576)$ & $0.034^{*}$ \\
\hline rs 2242652 & $5 \mathrm{p} 15.33$ & 1280028 & TERT & $\mathrm{A} / \mathrm{G}$ & 0.171 & 0.163 & 0.549 & $1.064(0.858-1.319)$ & 0.571 \\
\hline rs 2853677 & $5 \mathrm{p} 15.33$ & 1287194 & TERT & $\mathrm{G} / \mathrm{A}$ & 0.377 & 0.366 & 0.793 & $1.048(0.888-1.237)$ & 0.577 \\
\hline rs 2853676 & $5 \mathrm{p} 15.33$ & 1288547 & TERT & $\mathrm{T} / \mathrm{C}$ & 0.175 & 0.154 & 0.756 & $1.164(0.937-1.444)$ & 0.169 \\
\hline
\end{tabular}

SNP, single nucleotide polymorphism; MAF, minor allelic frequency; HWE, Hardy-Weinberg equilibrium; ORs, odds ratios; $\mathrm{CI}$, confidence interval.

a Minor allele; ${ }^{*} p$ value $\leq 0.05$ indicates statistical significance;

Table 3: Genotypes frequencies of the SNPs and their associations with risk of CHD

\begin{tabular}{|c|c|c|c|c|c|c|c|c|}
\hline \multirow{2}{*}{ SNP ID } & \multirow{2}{*}{ Alleles A/B } & \multirow{2}{*}{ Genotype } & \multicolumn{2}{|c|}{ Genotype frequencies } & \multicolumn{2}{|c|}{ Without adjustment } & \multicolumn{2}{|c|}{ With adjustment } \\
\hline & & & Case & Control & OR(95\%CI) & $p^{\text {a }}$ & OR(95\%CI) & $p^{b}$ \\
\hline \multirow[t]{3}{*}{ rs2075786 } & $\mathrm{G} / \mathrm{A}$ & $\mathrm{AA}$ & $419(70.3 \%)$ & $411(70.3 \%)$ & 1.00 & & 1.00 & \\
\hline & & GA & $160(26.8 \%)$ & $158(27.0 \%)$ & $\begin{array}{c}0.993(0.767- \\
1.286)\end{array}$ & 0.960 & $\begin{array}{c}0.925(0.688- \\
1.243)\end{array}$ & 0.605 \\
\hline & & GG & $17(2.9 \%)$ & $16(2.7 \%)$ & $\begin{array}{c}1.042(0.520- \\
2.091)\end{array}$ & 0.907 & $\begin{array}{c}0.972(0.431- \\
2.191)\end{array}$ & 0.945 \\
\hline \multirow[t]{3}{*}{ rs10069690 } & $\mathrm{T} / \mathrm{C}$ & $\mathrm{CC}$ & $396(66.4 \%)$ & $436(73.4 \%)$ & 1.00 & & 1.00 & \\
\hline & & $\mathrm{TC}$ & $186(31.2 \%)$ & $141(23.7 \%)$ & $\begin{array}{c}1.452(1.122- \\
1.879)\end{array}$ & $0.004 *$ & $\begin{array}{c}1.352(1.007- \\
1.815)\end{array}$ & $0.045^{*}$ \\
\hline & & $\mathrm{TT}$ & $14(2.4 \%)$ & $17(2.9 \%)$ & $\begin{array}{c}0.907(0.441- \\
1.863)\end{array}$ & 0.790 & $\begin{array}{c}1.020(0.452- \\
2.301)\end{array}$ & 0.961 \\
\hline \multirow[t]{3}{*}{ rs2242652 } & $\mathrm{A} / \mathrm{G}$ & GG & $404(67.8 \%)$ & $425(70.5 \%)$ & 1.00 & & 1.00 & \\
\hline & & $\mathrm{AG}$ & $180(30.2 \%)$ & $160(26.5 \%)$ & $\begin{array}{c}1.183(0.919- \\
1.524)\end{array}$ & 0.192 & $\begin{array}{c}1.088(0.817- \\
1.453)\end{array}$ & 0.569 \\
\hline & & AA & $12(2.0 \%)$ & $18(3.0 \%)$ & $\begin{array}{c}0.701(0.334- \\
1.474)\end{array}$ & 0.349 & $\begin{array}{c}0.693(0.297- \\
1.616)\end{array}$ & 0.396 \\
\hline \multirow[t]{3}{*}{ rs2853677 } & $\mathrm{G} / \mathrm{A}$ & AA & $225(37.8 \%)$ & $\begin{array}{c}244 \\
(40.5 \%)\end{array}$ & 1.00 & & 1.00 & \\
\hline & & GA & $293(49.2 \%)$ & $\begin{array}{c}277 \\
(46.0 \%)\end{array}$ & $\begin{array}{c}1.147(0.898- \\
1.465)\end{array}$ & 0.271 & $\begin{array}{c}1.163(0.880- \\
1.535)\end{array}$ & 0.288 \\
\hline & & GG & $78(13.0 \%)$ & $82(13.5 \%)$ & $\begin{array}{c}1.032(0.720- \\
1.477)\end{array}$ & 0.865 & $\begin{array}{c}1.259(0.834- \\
1.902)\end{array}$ & 0.272 \\
\hline \multirow[t]{3}{*}{ rs2853676 } & $\mathrm{T} / \mathrm{C}$ & $\mathrm{CC}$ & $405(68.0 \%)$ & $429(71.3 \%)$ & 1.00 & & 1.00 & \\
\hline & & TT & $173(29.0 \%)$ & $160(26.6 \%)$ & $\begin{array}{c}1.145(0.888- \\
1.477)\end{array}$ & 0.296 & $\begin{array}{c}1.153(0.862- \\
1.544)\end{array}$ & 0.337 \\
\hline & & $\mathrm{TC}$ & $18(3.0 \%)$ & $13(2.1 \%)$ & $\begin{array}{c}1.467(0.710- \\
3.032)\end{array}$ & 0.301 & $\begin{array}{c}1.896(0.838- \\
4.290)\end{array}$ & 0.124 \\
\hline
\end{tabular}

SNP, single nucleotide polymorphism; OR, odds ratio; 95\%CI, 95\% confidence interval.

${ }^{a} P$ values were calculated from unconditional logistic regression analysis.

${ }^{\mathrm{b}} P$ values were calculated by unconditional logistic regression analysis with adjustments for age and gender.

$* P \leq 0.05$ indicates statistical significance. 
Table 4: Association between rs10069690 and risk of CHD in multiple inheritance models (adjusted by age and gender)

\begin{tabular}{|c|c|c|c|c|c|c|c|c|c|c|c|}
\hline \multirow[b]{2}{*}{ Model } & \multirow[b]{2}{*}{ Genotype } & \multirow[b]{2}{*}{ Group $=$ case } & \multirow[b]{2}{*}{ Group $=$ control } & \multicolumn{4}{|c|}{ Without adjustment } & \multicolumn{4}{|c|}{ With adjustment } \\
\hline & & & & $\begin{array}{c}\text { OR }(95 \% \\
\text { CI) }\end{array}$ & $p$ & AIC & BIC & $\begin{array}{c}\text { OR }(95 \% \\
\text { CI) }\end{array}$ & $p$ & AIC & BIC \\
\hline \multirow[t]{3}{*}{$\begin{array}{l}\text { Co- } \\
\text { dominant }\end{array}$} & $\mathrm{C} / \mathrm{C}$ & $396(66.4 \%)$ & $436(73.4 \%)$ & 1 & $0.015^{*}$ & 1647.3 & 1662.5 & 1 & 0.13 & 1356.2 & 1381.6 \\
\hline & $\mathrm{C} / \mathrm{T}$ & $186(31.2 \%)$ & $141(23.7 \%)$ & $\begin{array}{c}1.45(1.12- \\
1.88)\end{array}$ & & & & $\begin{array}{c}1.35(1.01- \\
1.82)\end{array}$ & & & \\
\hline & $\mathrm{T} / \mathrm{T}$ & $14(2.4 \%)$ & $17(2.9 \%)$ & $\begin{array}{c}0.91(0.44- \\
1.86)\end{array}$ & & & & $\begin{array}{c}1.02(0.45- \\
2.30)\end{array}$ & & & \\
\hline \multirow[t]{2}{*}{ Dominant } & $\mathrm{C} / \mathrm{C}$ & $396(66.4 \%)$ & $436(73.4 \%)$ & 1 & $0.0088^{*}$ & 1646.8 & 1657 & 1 & 0.056 & 1354.7 & 1375 \\
\hline & $\mathrm{C} / \mathrm{T}-\mathrm{T} / \mathrm{T}$ & $200(33.6 \%)$ & $158(26.6 \%)$ & $\begin{array}{c}1.39(1.09- \\
1.79)\end{array}$ & & & & $\begin{array}{c}1.32(0.99- \\
1.75)\end{array}$ & & & \\
\hline \multirow[t]{2}{*}{ Recessive } & $\mathrm{C} / \mathrm{C}-\mathrm{C} / \mathrm{T}$ & $582(97.7 \%)$ & $577(97.1 \%)$ & 1 & 0.58 & 1653.4 & 1663.5 & 1 & 0.88 & 1358.3 & 1378.6 \\
\hline & $\mathrm{T} / \mathrm{T}$ & $14(2.4 \%)$ & $17(2.9 \%)$ & $\begin{array}{c}0.82(0.40- \\
1.67)\end{array}$ & & & & $\begin{array}{c}0.94(0.42- \\
2.11)\end{array}$ & & & \\
\hline \multirow[t]{2}{*}{$\begin{array}{l}\text { Over- } \\
\text { dominant }\end{array}$} & $\mathrm{C} / \mathrm{C}-\mathrm{T} / \mathrm{T}$ & $410(68.8 \%)$ & $453(76.3 \%)$ & 1 & $0.0039 *$ & 1645.3 & 1655.5 & 1 & $0.044^{*}$ & 1354.2 & 1374.5 \\
\hline & $\mathrm{C} / \mathrm{T}$ & $186(31.2 \%)$ & $141(23.7 \%)$ & $\begin{array}{c}1.46(1.13- \\
1.88)\end{array}$ & & & & $\begin{array}{c}1.35(1.01- \\
1.81)\end{array}$ & & & \\
\hline $\begin{array}{l}\text { Log- } \\
\text { additive }\end{array}$ & --- & --- & --- & $\begin{array}{c}1.27(1.02- \\
1.58)\end{array}$ & $0.033^{*}$ & 1649.1 & 1659.3 & $\begin{array}{c}1.23(0.96- \\
1.58)\end{array}$ & 0.1 & 1355.7 & 1376 \\
\hline
\end{tabular}

ORs, odds ratios; CI, confidence interval; AIC, Akaike's Information criterion; BIC, Bayesian Information criterion.

$* p$ value $\leq 0.05$ indicates statistical significance.

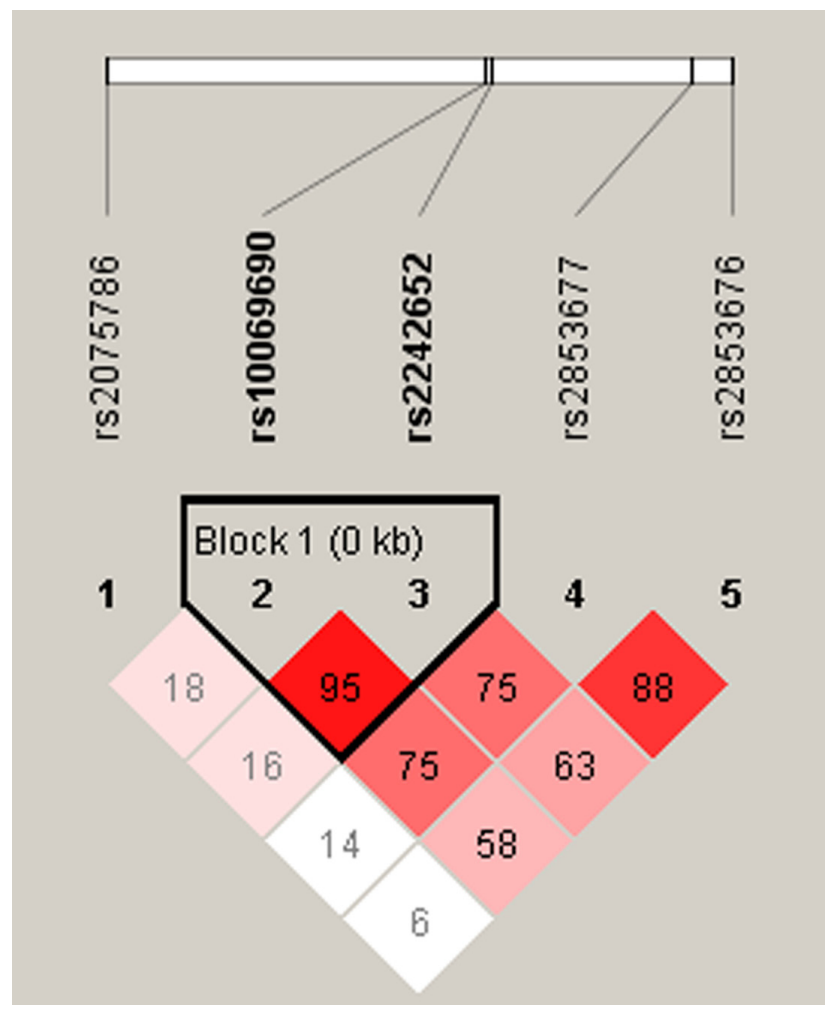

Figure 1: D' linkage map for the five SNPs in TERT. 
Table 5: TERT haplotype frequencies and the association with the CHD risk

\begin{tabular}{|c|c|c|c|c|c|c|c|c|}
\hline \multirow[b]{2}{*}{ Haplotype } & \multirow[b]{2}{*}{ rs10069690 } & \multirow[b]{2}{*}{ rs2242652 } & \multirow[b]{2}{*}{ Freq-case } & \multirow[b]{2}{*}{$\begin{array}{l}\text { Freq- } \\
\text { control }\end{array}$} & \multicolumn{2}{|c|}{ Without adjustment } & \multicolumn{2}{|c|}{ With adjustment } \\
\hline & & & & & $\begin{array}{c}\text { OR }(95 \% \\
\text { CI) }\end{array}$ & $p$ & $\begin{array}{c}\text { OR }(95 \% \\
\text { CI) }\end{array}$ & $p$ \\
\hline 1 & $\mathrm{C}$ & G & 0.818 & 0.832 & 1 & --- & 1 & --- \\
\hline 2 & $\mathrm{~T}$ & A & 0.169 & 0.146 & $\begin{array}{c}1.17(0.94- \\
1.46)\end{array}$ & 0.16 & $\begin{array}{c}1.11(0.86- \\
1.44)\end{array}$ & 0.41 \\
\hline rare & $*$ & $*$ & 0.013 & 0.022 & $\begin{array}{c}0.61(0.32- \\
1.16)\end{array}$ & 0.13 & $\begin{array}{c}0.72(0.35- \\
1.46)\end{array}$ & 0.36 \\
\hline
\end{tabular}

Freq, frequency; ORs, odds ratios; CI, confidence interval.

Table 6: Primers used for this study

\begin{tabular}{|c|c|c|c|}
\hline SNP_ID & First PCR Primer & Second PCR Primer & UEP SEQ \\
\hline rs2075786 & ACGTTGGATGCAGGTTACACACGTGGTGAG & ACGTTGGATGCGCCACTCTTGACTTTCCAA & ggCAAAGAGCAGCAGGAGCC \\
\hline rs 10069690 & ACGTTGGATGCCTGTGGCTGCGGTGGCTG & ACGTTGGATGATGTGTGTTGCACACGGGAT & GGGATCCTCATGCCA \\
\hline rs 2242652 & ACGTTGGATGACAGCAGGACACGGATCCAG & ACGTTGGATGAGGCTCTGAGGACCACAAGA & gtcgGAGGACCACAAGAAGCAGC \\
\hline rs 2853677 & ACGTTGGATGATCCAGTCTGACAGTCGTTG & ACGTTGGATGGCAAGTGGAGAATCAGAGTG & gggtAATCAGAGTGCACCAG \\
\hline rs 2853676 & ACGTTGGATGTGTCTCCTGCTCTGAGACC & ACGTTGGATGCAAAACTAAGACCCAAGAGG & agatGGAAGTCTGACGAAGGC \\
\hline
\end{tabular}

UEP SEQ, unextended mini-sequencing primer.

CHD risk in populations of European ancestry [16]. Tang, Wang, $\mathrm{Lu}$ et al. have replicated these locus and explore novel loci in the Chinese population, including rs6903956, rs1842896, rs2123536, rs7136259 and rs9268402 [17-19]. In the present study, we selected five SNPs in TERT gene, including rs2075786, rs10069690, rs2242652, rs2853677 and rs2853676. Rs2075786 was found to be associated with paranoid schizophrenia [20] and colorectal cancer risk. However, the results were inconsistent [21, 22]. In our study, we didn't observe any association between rs2075786 and CHD risk. Rs 10069690 was found to be associated with breast cancer [23], hepatocellular carcinoma and tumor metastasis [24]. We are the first to report that rs 10069690 was associated with increased risk of CHD, which need to be confirmed in further studies. For the remaining three SNPs rs2242652, rs2853677 and rs2853676, Nan et al. reported that rs2242652 and rs2853676 were associated with risk of melanoma [25]. Recently, Li et al. reported that rs2853677 modulates Snaill binding to the TERT enhancer and affects lung adenocarcinoma susceptibility [26]. However, little information is found about the association between these SNPs and CHD risk. We didn't detect any association between rs2242652, rs2853677 and rs2853676 and CHD risk, either.

The present study has several potential limitations. First, the sample size is relatively small, and the participants included only Chinese population lived in Shaanxi Province. Second, CHD is a multifactoral disease that contains several complex genetic and environmental factors. We could not completely eliminate the potential influences of environmental factors on the results. Therefore, the interaction of genetic and environmental factors in the development of CHD need be confirmed in further studies with a larger and multifarious sample.

In sum, our results indicate that TERT rs 10069690 is associated with an increased risk of CHD, which may has the potentially to serve as prognostic biomarker for CHD among the Chinese Han population. Further study will focus on validating our findings with a larger sample and on determining the functional role of these SNPs.

\section{MATERIALS AND METHODS}

\section{Ethics statement}

We strictly obeyed the World Medical Association Declaration of Helsinki when using human tissue and signing the study protocol with subjects, which was approved by the Ethical Committee of Weinan Central Hospital. Each participant provided written, informed consent.

\section{Subjects}

All participants in our study were Han Chinese. A total of 596 CHD patients and 603 healthy controls were consecutively recruited between January 2014 and May 2016 in the Weinan Central Hospital in Weinan city, China. Patients were diagnosed with CHD using standard coronary angiography, which revealed $\geq 70 \%$ stenosis of the main branch of a coronary artery or aortic stenosis $\geq$ 
$50 \%$. Subjects with myocardial infarction, stable angina and unstable angina were classified as CHD subjects. There were no age, sex or disease-stage classification restrictions when enrolling the case group. Controls were healthy people receiving physical examinations in other clinical departments of Weinan Central Hospital. Healthy controls have no congenital heart disease, familial hypercholesterolemia, end-stage renal disease and known vasculitides, which could have affected our study results. Peripheral blood was collected from both cases and controls for DNA extraction.

\section{SNP selection and genotyping}

Candidate SNPs in the TERT gene were selected from previous publications that associated polymorphisms with telomere length $[27,28]$. SNPs with minor allele frequencies (MAF) $>5 \%$ in the HapMap CHB population were selected. We validated five SNPs in TERT. The GoldMag-Mini Purification Kit (GoldMag Co. Ltd. Xian city, China) was used to extract genomic DNA from whole blood samples. DNA concentration was measured using a DU530 UV/VIS spectrophotometer (Beckman Instruments, Fullerton, CA, USA). Using MassARRAY Assay Design 3.0 software (Sequenom, San Diego, CA, USA), we designed a multiplexed SNP MassEXTENDED assay [29]. SNPs were genotyped using the standard protocol recommended by the MassARRAY RS1000 (Sequenom) manufacturer and data were analyzed using Typer 4.0 Software (Sequenom). Primers used for this study were listed in Table 6 .

\section{Statistical analysis}

We used Microsoft Excel and SPSS 17.0 (SPSS, Chicago, IL) statistical packages to perform statistical analyses. All $p$-values were two-sided and $p<0.05$ was considered statistically significant. A $t$ test and Chi-square test were performed to compare sex and age differences between cases and controls. Fisher's exact test was applied to each SNP in the controls to test for departure from Hardy-Weinberg Equilibrium (HWE). Odds ratios (ORs) and 95\% confidence intervals (CIs) for the allele and genotype frequencies were calculated using Pearson Chi-square test adjusted by age and sex [30]. Five models (co-dominant, dominant, recessive, over-dominant and log-additive) were used to assess the association between each genotype and the risk of CHD. The effects of the polymorphisms on the risk of CHD were expressed as ORs with $95 \%$ CIs, which were calculated using unconditional logistic regression analysis after adjusting for age and gender [31]. Akaike's information criterion (AIC) and Bayesian information criterion (BIC) were applied to choose the best-fit model for each SNP. Finally, linkage disequilibrium (LD) patterns and haplotypes were evaluated using the Haploview software package (version 4.2) [32].

\section{CONFLICTS OF INTEREST}

The authors have no conflicts of interest to report.

\section{REFERENCES}

1. Gaziano TA. Cardiovascular disease in the developing world and its cost-effective management. Circulation. 2005; 112:3547-3553.

2. Lopez AD, Mathers CD, Ezzati M, Jamison DT, Murray CJ. Global and regional burden of disease and risk factors, 2001: systematic analysis of population health data. Lancet. 2006; 367:1747-1757.

3. Gaziano TA. Reducing the growing burden of cardiovascular disease in the developing world. Health Aff (Millwood). 2007; 26:13-24.

4. Wang Q. Molecular genetics of coronary artery disease. Am J Hum Genet. 2005; 20:182-188.

5. Peden JF, Farrall M. Thirty-five common variants for coronary artery disease: the fruits of much collaborative labour. Hum Mol Genet. 2011; 20:R198-R205.

6. Deloukas P, Kanoni S, Willenborg C, Farrall M, Assimes TL, Thompson JR, Ingelsson E, Saleheen D, Erdmann J, Goldstein BA, Stirrups K, Konig IR, Cazier JB, et al. Large-scale association analysis identifies new risk loci for coronary artery disease. Nat Genet. 2013; 45:25-33.

7. Moon IK, Jarstfer MB. The human telomere and its relationship to human disease, therapy, and tissue engineering. Front Biosci. 2007; 12:4595-4620.

8. Aubert G, Lansdorp PM. Telomeres and aging. Physiol Rev. 2008; 88:557-579.

9. Mirabello L, Kai Y, Kraft P, Vivo ID, Hunter DJ, Prescott J, Wong JY, Chatterjee N, Hayes RB, Savage SA. The association of telomere length and genetic variation in telomere biology genes a. Hum Mutat. 2010; 31:1050-1058.

10. Greider CW. Telomerase activity, cell proliferation, and cancer. Proc Natl Acad Sci U S A. 1998; 95:90-92.

11. Wu X, Amos CI, Zhu Y, Zhao H, Grossman BH, Shay JW, Luo S, Hong WK, Spitz MR. Telomere dysfunction: a potential cancer predisposition factor. J Natl Cancer Inst. 2003; 95:1211-1218.

12. Codd V, Nelson CP, Albrecht E, Mangino M, Deelen J, Buxton JL, Hottenga JJ, Fischer K, Esko T, Surakka I. Identification of seven loci affecting mean telomere length and their association with disease. Nat Genet. 2013; 45:422-427.

13. Palm $\mathrm{W}$, de Lange $\mathrm{T}$. How shelterin protects mammalian telomeres. Annu Rev Genet. 2008; 42: 301-334.

14. Brouilette S, Moore J, McMahon AD, Thompson J, Ford I, Shepherd J, Packard C, Samani N; West of Scotland Coronary Prevention Study Group. Telomere length, risk of coronary heart disease, and statin treatment in the West of Scotland Primary Prevention Study: a nested case-control study. Lancet. 2007; 369:107-114. 
15. Rafnar T, Sulem P, Stacey SN, Geller F, Gudmundsson J, Sigurdsson A, Jakobsdottir M, Helgadottir H, Thorlacius $\mathrm{S}$, Aben KK. Sequence variants at the TERT-CLPTM1L locus associate with many cancer types. Nat Genet. 2009; 41:221-227.

16. Samani NJ, Deloukas P, Erdmann J, Hengstenberg C, Kuulasmaa K, McGinnis R, Schunkert H, Soranzo N, Thompson J, Tiret L, Ziegler A. Large scale association analysis of novel genetic loci for coronary artery disease. Arterioscler Thromb Vasc Biol. 2009; 29:774-780.

17. Tang NP, Wang LS, Yang L, Gu HJ, Sun QM, Cong RH, Zhou B, Zhu HJ, Wang B. Genetic variant in glutathione peroxidase 1 gene is associated with an increased risk of coronary artery disease in a Chinese population. Clin Chim Acta. 2008; 395:89-93.

18. Wang F, Xu CQ, He Q, Cai JP, Li XC, Wang D, Xiong X, Liao YH, Zeng QT, Yang YZ, Cheng X, Li C, Yang R, et al. Genome-wide association identifies a susceptibility locus for coronary artery disease in the Chinese Han population. Nat Genet. 2011; 43:345-349.

19. Lu X, Wang L, Chen S, He L, Yang X, Shi Y, Cheng J, Zhang L, Gu CC, Huang J, Wu T, Ma Y, Li J, et al. Genomewide association study in Han Chinese identifies four new susceptibility loci for coronary artery disease. Nat Genet. 2012; 44:890-894.

20. Rao S, Ye N, Hu H, Shen Y, Xu Q. Variants in TERT influencing telomere length are associated with paranoid schizophrenia risk. Am J Med Genet B Neuropsychiatr Genet. 2016; 171:317-324.

21. Philipp H, Andreas B, Kathrin B, Gernot L, Karl M, Michael M, Andrea G. Association of genetic variants of human telomerase with colorectal polyps and colorectal cancer risk. Mol Carcinog. 2012; 51:E176.

22. Win AK, Clendenning M, Crawford W, Rosty C, Preston SG, Southey MC, Parry S, Giles GG, Macrae FA, Winship IM. Genetic variants within the hTERT gene and the risk of colorectal cancer in Lynch syndrome. Genes Cancer. 2015; 6:445-451. doi: 10.18632/genesandcancer.85.
23. Li ZY, Dong YL, Feng Y, Zhang Z, Cao XZ. Polymorphisms in the telomerase reverse transcriptase promoter are associated with risk of breast cancer: a meta-analysis. J Cancer Res Ther. 2016; 12:1040-1044.

24. Dong J, Wang L, Tian YP, Guo Y, Liu HY. [hTERT single nucleotide polymorphism is associated with increased risks of hepatocellular carcinoma and tumor metastasis]. [Article in Chinese]. Nan Fang Yi Ke Da Xue Xue Bao. 2011; 31:49-52. Journal of Southern Medical University. 2011; 31:49-52.

25. Nan H, Qureshi AA, Prescott J, Vivo ID, Han J. Genetic variants in telomere-maintaining genes and skin cancer risk. Hum Genet. 2011; 129:247-253.

26. Li X, Xing X, Fang J, Lin W, Mu Y, Peng Z, Zhi Y, Ma Z, Zhe L. Rs2853677 modulates Snaill binding to theTERTenhancer and affects lung adenocarcinoma susceptibility. Oncotarget. 2016; 7:37825-37838. doi: 10.18632/oncotarget.9339.

27. Bojesen SE, Pooley KA, Johnatty SE, Beesley J, Michailidou K, Tyrer JP, Edwards SL, Pickett HA, Shen $\mathrm{HC}$, Smart CE. Multiple independent variants at the TERT locus are associated with telomere length and risks of breast and ovarian cancer. Nat Genet. 2015; 45:371-384.

28. Melin BS, Nordfjäll K, Andersson U, Roos G. hTERT cancer risk genotypes are associated with telomere length. Genet Epidemiol. 2012; 36:368-372.

29. Gabriel S, Ziaugra L, Tabbaa D. SNP genotyping using the Sequenom MassARRAY iPLEX platform. Curr Protoc Hum Genet. 2009; 2:2.12.

30. Adamec C. Example of the use of the nonparametric test. Test X2 for comparison of 2 independent examples. Ceskoslovenské zdravotnictví. 1964; 12:613.

31. Bland JM, Altman DG. Statistics notes. The odds ratio. BMJ. 2000; 320:1468.

32. Yong Y, Lin H. SHEsis, a powerful software platform for analyses of linkage disequilibrium, haplotype construction, and genetic association at polymorphism loci. Cell Res. 2005; 15:97-98. 